International Peacekeeping

\title{
Culture and Legitimacy in Peacebuilding Settings
}

\section{Roberta Holanda Maschietto}

To cite this article: Roberta Holanda Maschietto (2017): Culture and Legitimacy in Peacebuilding Settings, International Peacekeeping, DOI: 10.1080/13533312.2017.1392859

To link to this article: https://doi.org/10.1080/13533312.2017.1392859

\section{Published online: 02 Nov 2017.}

Submit your article to this journal 단

\section{Article views: 12}

Q View related articles $₫$

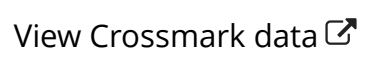




\section{BOOK REVIEW}

\section{Culture and Legitimacy in Peacebuilding Settings}

The cultural dimension of peace: decentralization and reconciliation in Indonesia, by Birgit Bräuchler, Basingstoke, Palgrave Macmillan, Rethinking Peace and Conflict Studies Series, 2015, pp.208 + bibliography + notes + index, $£ 38.93$ (hbk), ISBN 978-1-4039-9575-9

\section{Liberal peacebuilding and the locus of legitimacy, edited by David Roberts, London and New York, Palgrave, 2015, pp.104 + index, £105.00 (hbk), ISBN13 9781138801356}

Subjective aspects of peace have long been neglected in the peacebuilding literature. With notable exceptions such as the work of John Paul Lederach, through the 1990s and 2000s, an emphasis on technocratic solutions for peace culminating in the statebuilding formula has been the main concern of international institutions and actors involved in peacebuilding. More recently, however, following the expansion of the 'local turn' and the refinement of more critical approaches to peacebuilding, cultural aspects and subjectivities have gained prominence in the literature. The Cultural Dimension of Peace: Decentralization and Reconciliation in Indonesia by Birgit Bräuchler and Liberal Peacebuilding and the Locus of Legitimacy edited by David Roberts constitute two important contributions to this debate. Both books engage with critical approaches in peacebuilding scholarship, and each one, albeit in different ways, explores important nuances related to the debate on culture and legitimacy in peacebuilding settings.

Bräuchler offers an insightful discussion about the 'cultural turn' in peacebuilding, pointing to its achievements and limitations and grounding her analysis in an in-depth ethnographic study of the Moluccas in Eastern Indonesia. Despite her narrow geographical focus, the book is of great value to anyone interested in ethnography and peacebuilding, particularly because of the author's ability to successfully link a broad theoretical debate on culture, transitional justice and reconciliation to a very detailed, grounded, everyday analysis of peace. The empirical analysis, in turn, is used to demonstrate not only that local aspects of peace matter - as much recent scholarship has shown - but also, and more importantly, that a more thorough use of the anthropological approach in peacebuilding is called for. On the one hand, Bräuchler corroborates the idea that researchers need to consider local aspects, in particular, culture and traditional means of conflict resolution, in the analysis of peacebuilding, since such aspects reveal 'what conflict and peace mean for local societies and ... it can anchor reconciliation on the ground and make peacebuilding sustainable' (xviii). On the other hand, and considering the current emphasis on decentralization and the revival of tradition in post-conflict settings, she also cautions that 'the enthusiasm for revival 
[is] an excuse for governments and others to refrain from solving long-term structural problems and addressing root causes of the conflicts, measures that are, in the long run, important for a stable and lasting peace' (xviii). In this regard, the book is an important reminder about the dangers of instrumentalizing culture as well as taking a superficial anthropological stand by harmonizing and unifying the 'local'.

Structurally, the book comprises seven chapters, as well as a brief introduction. The first is devoted to the discussion of the 'cultural turn' in peacebuilding. Here, Bräuchler stresses that an anthropological approach to peacebuilding is needed because such discipline and its methods help reveal 'prospects and problems of traditional justice, flawed concepts of culture and tradition, and misconceptions based on a superficial (ac)knowledge(ment) of the local' (1). Discussing the concepts of transitional justice and reconciliation, she points to how ambiguous they may be, even though they are usually included in the peacebuilding toolkit alongside other Western principles that are at the base of the liberal peace. The problem is that ideas of truth and justice differ according to different cultural values and worldviews. Additionally, technocratic approaches to transitional justice and reconciliation ignore the fact that, in practice, these are highly political processes, where questions such as 'who defines culture and tradition on the local level?' and 'who has what interests in the revival or masking of traditions?' matter. Because of this, such processes need to be contextualized in order to be better understood, or else initiatives such as the integration of traditional justice into peacebuilding mechanisms may end up reinforcing inequalities and hierarchies instead of contributing to a local and even international ideal of justice. This discussion alone is of utmost relevance in the context of the 'local turn' in peacebuilding. Because the emphasis on the local came as a reaction to top-down actions by international actors, the analysis of power asymmetries has often been circumscribed to the useful yet problematic international/local dichotomy. While some academics have made an effort to further problematize the local, such as Oliver Richmond's use of the term 'local-local', power relations at the local level still need to be explored in much greater depth, in particular with regard to how they affect the quality of peace that is built after a violent conflict.

This is the context that frames the following chapters of Bräuchler's book and the study of the reconciliation and transitional justice processes in Indonesia. Chapter 2 offers an overview of the process of decentralization in that country, focusing on the concept of adat. Adat means 'custom' or 'habit', and has been used across the country as a synonym for local tradition and customary law, but differing in its practice from locality to locality. Bräuchler notes that the strength of adat resides precisely in its flexibility. In fact, regardless of several attempts to define it and codify it, it is the case that 'Conflict resolution à la adat does not follow any prescribed schemes to inquire into an isolated case, but is contextual and situational' (45). Because of this, the revival of adat in post-Suharto Indonesia in the context of decentralization has been quite problematic. For one, there have been disputes regarding the claim for legitimacy of adat, which involves many interest groups. Moreover, as adat has been used traditionally to solve intracommunity conflicts, it has been unable to cope with many 
of the post-Suharto conflicts, which involve mass violence and are inter-ethnic or interreligious. Such limitations have indeed suggested that the efficiency of adat in such contexts would depend on its ability to engage with broader formal legal mechanisms of conflict resolution. Ultimately, underlying the ambivalences about decentralization and the revival of adat is the central question of 'what adat we are actually talking about and who defines what an authentic tradition in a particular context is' (57), a question that also begs going back into colonial times as the author exhaustively demonstrates in the chapter.

Chapter 3 narrows the analysis to the case of Maluku, an archipelago in Eastern Indonesia, where Bräuchler conducted multi-sited and multi-temporal ethnographic fieldwork. In 1999, mass violence took place in Maluku, involving Muslims and Christians and lasting for more than four years, causing thousands of deaths, producing thousands of refugees and triggering substantial destruction of religious, civil and educational infrastructure. This chapter provides a comprehensive description of the conflict as well as of the many peacebuilding initiatives that took place in Maluku, while also noting how often they were uncoordinated and ended up in competition. As Bräuchler observes, while the dynamics surrounding conflict and peace were manifold, a common theme underlying peacebuilding efforts was the revival of tradition, an aspect that is discussed in much more detail in the following chapters.

Chapter 4 examines the revival of tradition and its role in reconciliation in Maluku, as well as the ambiguous role of adat. As noted, while in the context of conflict adat was sometimes used as a means to promote violence (for instance, when the blessing of adat priests was sought before attacks), it also became a central pillar to promote peace. In fact, 'adat appeared to be the only seemingly neutral means readily available to all Moluccans' (101). In this context, of particular relevance to reconciliation at the local level were traditional alliances, family ties and even the local economy, which often transcended the role of religious affiliation and prevented communities from engaging in violence against each other. At the same time, the use of adat in the context of decentralization was quite ambivalent, with the key issue being how adat was interpreted and who would have the final say in its revival. In fact, while adat is supposed to integrate society as a whole, in its current form, it has not been able to accommodate the complexity and the heterogeneity of the population. Besides, while enabling the restoration of local autonomy, thus contributing to decentralization, it also challenges international values of democracy and human rights, often reviving what are considered to be feudalistic structures and restoring old hierarchies.

This particular issue is further considered in Chapter 5, where special attention is given to the role of the rajas, traditional village heads, who were key in the process of decentralization and peacebuilding in Maluku. As in many other post-colonial settings, the rajas and their status were not detached from the dynamics of colonialism. As such, the revaluation of the raja was not free of controversy. First, historically, their revaluation meant the devaluation or marginalization of other adat key figures. Second, their very role underwent so many changes that their legitimacy and representativeness were often questioned. Indeed, while rajas are traditional village heads and important representatives 
of the local adat system, they also stand for a (formerly) feudal hierarchical system. Moreover, in the decentralization era, 'they are again both representatives of the local people and representatives of the Indonesian government' (131). This further affects the raja's ability to promote conflict resolution.

Chapter 6 dives deeper into the issue of representativeness by discussing the complex and delicate debate about cultural human rights and how they may clash with the principles of individual human rights. In Indonesia, this is particularly important with regard to returning migrants and refugees, land claims, and how this all engages with the revival of adat. Indeed, Bräuchler notes that, ultimately, adat is an ambivalent criterion for defining indigeneity in Indonesia. In fact, it has often been used as a reason to expel people and to refuse or allow their return. The challenge is thus how to integrate returnees and 'to convince not only cultural insiders to open up their traditional concepts, but also those excluded to accept the newly reconstructed (or revived) means for integration' (160). This entails a thorough discussion about legal pluralism and how to coordinate systems that often contradict each other.

Chapter 7 concludes the book by reflecting on the Moluccan case and stressing the need for a 'new anthropology of peace'. As demonstrated by the detailed empirical analysis of Maluku, the point Bräuchler emphasizes is that the revival of tradition and traditional justice mechanisms as a means for peace is ambivalent, in the sense that it has the potential both for peace and for conflict. The key issue is thus to 'strategically select and adapt traditions, thus accommodating the needs of a post-conflict society and/or their own interests' (180), which is challenging, yet possible. The case for reviving traditional mechanisms for peacebuilding is fundamentally based on the legitimacy they may help foster at the local level, which should not be underestimated. At the same time, practitioners need to pay attention to the sensitive issues underlying such revival, not least the conflicts of interest that exist at the local level. The role of anthropology, in this context, is precisely to allow a better understanding of the construction of such patterns of authority and legitimacy and thus facilitate a critical and grounded reflection of what 'local', 'legitimacy' and 'culture' stand for. In particular, longterm ethnographic research is useful to trace the many changes that characterize different societies and how such changes may contribute to peace and conflict, as well as the possibility of adaptation of traditional mechanisms in order to promote peace and reconciliation.

Bräuchler's reflections are very insightful and resonate with other ethnographic studies related to peacebuilding, decentralization and the revival of tradition, not only in Asia, but also in African countries, such as Mozambique and Sierra Leone. Her careful consideration of the cultural turn, the problematization of culture itself and the acknowledgement that tradition can be used for both peace and conflict are an important reminder of the need not to romanticize the local. In fact, her analysis points to the need for researchers to engage more closely with issues of power -the power asymmetries not only between 'internationals' and 'locals', but also within the national and local domains. Ultimately, the way those multiple levels of analysis mingle and correlate alters the spaces for social transformation and the potential emancipatory effects of peace. That 
said, her analysis also corroborates the idea that focusing on the micro-level is a must for a more thorough understanding of the successes and failures of peacebuilding activities, in particular, governance reforms and reconciliation processes. Regardless of the many problems related to the adat system, the latter ultimately offered an important space for the legitimization of peacebuilding at the local level because it engaged with the language of local actors.

Another relevant feature of Bräuchler's work is her emphasis on long-term ethnography. As ethnography becomes an increasingly important research instrument in peacebuilding studies, it is important to deepen the study of this methodology, including the many forms it can take and its limitations. In this regard, The Cultural Dimension of Peace also complements recent studies on ethnography in peacebuilding, such as the work of Gearoid Millar, highlighting the nuances and challenges that accompany this methodological choice.

While different in nature, David Roberts' edited volume stems from a similar concern to Bräuchler's. At its base, it is driven by the same call to 'go local' and thoroughly assess the extent to which peacebuilding assumptions and claims make sense on the ground, at the level of the everyday. The driving question of what was first launched as a special issue of the Journal of Intervention and Statebuilding (March 2013) was 'what priorities and institutions would generate local legitimacy and thence more relevant and sustainable relations and peace without being solely and implausibly indigenous?' (2). To answer this question, the book presents 6 chapters, each one rich in empirical material related to different countries and specific agendas of peacebuilding, as well as theoretical reflections concerning legitimacy and statebuilding/peacebuilding.

The first chapter is a brief introduction by Roberts, which sets the stage for the general debate in the book. Roberts aligns with the critical literature in peacebuilding, in which the need to question the ontologies and epistemologies of the liberal peace are taken as a must. From this perspective, legitimacy is fundamentally linked to the validation that comes from within, that is, from the local setting, in contrast to the adaptation to international norms in a top-down process that lies at the core of the mainstream peacebuilding agenda. Ultimately, it is this legitimacy that is at the base of a valid and stable social contract and that can contribute to peace in the long term.

The subsequent chapters generally all validate this overall argument and explore different nuances of the debate on legitimacy, while providing rich empirical examples. In Chapter 2, Stefanie Kappler discusses the case of Bosnia-Herzegovina and how legitimacy has moved from the public space to new semi-public spaces. She argues that the Dayton Peace Agreement has encouraged people to define their identities primarily as ethnic. This, in turn, has led to a dissociative political setting that ends up favouring the elites of politics and the market, instead of contributing to a general space of reintegration. As the traditional 'public space' (the formal setting where political engagement and governance take place) has been perceived as distant from the masses, a reaction has occurred, leading to the construction of new 'semi-public' spaces, in this case, portrayed here in the context of the cultural arena (e.g. theatre, music, etc.). Such spaces have provided a place where the public and the private meet, 
regardless of ethnic differences. They make sense locally, creating a feeling of ownership, which in turn reinforce their legitimacy. Moreover, they are free from the negative connotations linked to the political arena, while also providing space for political agency, for example, through education and cultural exchange.

In a different fashion, Stuart Gordon, in Chapter 3, discusses the relationship between service delivery - in this case health care - and the construction of legitimacy in statebuilding settings. Exploring the existing literature on health systems and peacebuilding, Gordon notices that there is a discourse that emphasizes the potential for a functional health system to contribute to the legitimation of the state by strengthening the social contract. While there are several arguments supporting such a link, the existing empirical evidence, here discussed and presented, contests such claims. There is, in fact, no clear evidence demonstrating this link, and instead the relationship between health, peace and statebuilding is shown to be far more complex, requiring far more empirical investigation.

In Chapter 4, Simon Robins discusses yet another different aspect of legitimacy, namely the very definition of priorities in peacebuilding contexts and the gap between local and international views of what is fundamental for peace. Key to his argument is the debate on what constitutes legitimacy. While peacebuilders focus on institutional aspects of legitimacy (set beforehand by predefined global benchmarks), it is performance legitimacy that matters at the local level. Presenting solid empirical data from Timor-Leste and Nepal and focusing on the international efforts at promoting reconciliation, Robins notes that an emphasis on rights, public hearings and trials had little resonance with local expectations and views about justice and reconciliation. The author also found that spiritual needs and economic needs were perceived as far more important locally than those usually prioritized by international peacebuilders, and they were virtually neglected by the latter, thus creating a gap between local expectations and what was delivered by peacebuilders.

Roberts makes a similar point in Chapter 5. Taking a critical stand on the liberal peacebuilding paradigm, he highlights the need to engage with what makes sense at the local level without carrying a predefined ideological or theoretical agenda. Again, the role of performance legitimacy at the local level is emphasized and he uses the empirical example of Southern Sudan, where people were asked in a survey what they wanted their government to prioritize. The answers overwhelmingly showed that development issues were at the top of their list, even before democracy. The survey also showed that 'democracy' had very different connotations compared to Western notions, as it also entailed a strong connection with development and socio-economic issues.

The practical problems of generating legitimacy from the top-down are finally illustrated by Nicolas Lemay-Hébert in the case of Kosovo (Chapter 6). Starting from a critical take on the Weberian concept of legitimacy and how the latter informs the entire statebuilding agenda, he stresses how legitimacy also needs to be understood in terms of its origins and the structural conditions and power that provide its shape, as well as in terms of people's beliefs. Referring to the crisis of legitimacy faced by the UN Special Representative of the Secretary-General in Kosovo, who exercised 'government authority' in that territory 
between 1999 and 2004, Lemay-Hébert notes how the latter suffered from a 'legitimacy dilemma' (93), that is, 'much of what international administrators do to reinforce their rule also perpetuates their weakness'. In Kosovo, this meant that, regardless of some successes of the transitional administration in the first months after the conflict, over time increased resistance emerged towards what was perceived as an external bureaucratic machine (UNMIK) not accountable to the population. Accordingly, when violent riots took place in 2004, even though many movements were involved and there was clearly an inter-ethnic aspect framing the violence, the blame fell over UNMIK and KFOR (NATO's Kosovo Forces), the 'alien' actor.

Through the provision of so many different empirical studies, Robert's edited volume makes a rich contribution to the debate on legitimacy in peacebuilding. Taken together, the case studies resonate with some of the general findings presented in Bräuchler's work, namely the fact that subjective elements, that is, how local actors interpret particular concepts at the base of liberal peacebuilding, not only matter, but also and more importantly influence local responses to international action, as well as shape local expectations towards peace. At the same time, the volume also shows that much more empirical research is needed to better understand the dynamics of legitimacy and the functioning of the social contract. In fact, all contributions in the book point to the need to reconsider specific concepts that have shaped Western thinking about the relationship between state and society so they can be better related to the daily experiences of the actors involved in peacebuilding.

It is important to note that other studies have touched on several aspects explored in both books. The ambiguities of tradition and its politicization in the context of decentralization reforms, for instance, have been discussed in other settings, as has the role of legitimacy in peacebuilding and how this relates to the need to put culture centre stage. Yet, what is key in these two volumes is the authors' efforts to systematize such debates and explore their nuances. Since one of the critiques of the critical turn in peacebuilding is precisely the lack of general theorizing and the excessive emphasis on case studies, it is indeed important to organize existing studies so that their contribution to the general debate is clear. In this regard, the increasing number of ethnographic studies and their comparison allow us to see that some of the problems discussed at the local level are far from unique. At the same time, the fact that several commonalities are observable at the micro level reinforces the critical call for more contextualized practices in peacebuilding, which, in turn, compel us to engage with alternative epistemologies so that we can better understand the social world we are researching.

More generally, both books also point towards the concrete challenges related to the implementation of peacebuilding and statebuilding while being sensitive to issues of legitimacy. At the same time, and notwithstanding Bräuchler's note about the ambivalence of tradition, both books end with a fairly positive note regarding the possibility of external actors engaging with local subjectivities in order to promote more legitimate peace. Other researchers may reach different conclusions, especially when exploring such delicate topics such as gender 
issues and even the different functions attributed to the use of violence in certain communities. Some may indeed argue that even in the West a certain degree of top-down dynamics, reflected in the creation of the state, was fundamental to reducing violence and fostering liberal values that, ultimately, helped to protect individual (and human) rights. This is definitely a complex debate, framed by normative standards, which requires not only more empirical research - particularly comparative empirical research - but also a profound historical reflection on the constitution of both Western and non-Western societies.

In sum, these two books help advance some of these questions, opening the doors for further discussion regarding culture and legitimacy in peacebuilding. I enthusiastically recommend both volumes to both academics and practitioners of peacebuilding, while also joining the authors' call for a broader engagement for all of us with alternative epistemologies.

Roberta Holanda Maschietto

Centre for Social Studies, University of Coimbra (2) robertahm@ces.uc.pt (iD http://orcid.org/0000-0002-6079-280X

(C) 2017 Roberta Holanda Maschietto https://doi.org/10.1080/13533312.2017.1392859 